\title{
Effects of the Pre-Cooking Process Using Acetic Acid and Citric Acid on Lead Concentration in Rice
}

\section{Roya Behrouzi ${ }^{1}$, Mohammd Hosein Marhamatizadeh ${ }^{2 *}$,Vadood Razavilar ${ }^{1}$, Hossein Rastegar ${ }^{3,4}$, Shahram Shoeibi ${ }^{3,4}$}

${ }^{1}$ Departmentof Veterinary Medicine, Science and Research Branch, Islamic Azad University, Tehran, Iran ${ }^{2}$ Department of Food Hygiene, Faculty of Veterinary Medicine,Kazerun Branch, Islamic Azad University, Kazerun, Iran ${ }^{3}$ Food and Drug Control Laboratory Reference Center, Food and Drug Organization, Ministry of Health and Medical Education, Tehran, Iran

${ }^{4}$ Food and Drug Laboratory Research Center, Food and Drug Organization, Ministry of Health and Medical Education, Tehran, Iran

Received: 5 February 2018

Accepted: 17 April 2018

\begin{abstract}
Rice is one of the most highly consumed foodstuffs in the world. In keeping with this, produced rice of many regions of the world contains high lead content. The present research was done to study the effects of the pre-cooking process of rice with acetic acid and citric acid on the concentration of lead. Rice samples were divided into 5 different pre-cooking treatment groups of soaking in acetic acid $1 \%$ and soaking in citric acid $1 \%(2 \mathrm{hrs})$, boiling with acetic acid $1 \%$ and boiling with citric acid $1 \%(20 \mathrm{~min})$ and finally 6 times rinsing with deionized water. Then, measurement of lead remains was done using an atomic absorption optical spectrometer equipped with a detector of graphite furnace with deuterium lamp. The mean concentration of lead in primary rice samples without any processing operation was $87 \pm 4.8 \mathrm{ppb}$. The mean concentration of lead in rice samples processed with soaking in acetic acid, soaking in citric acid, boiling with citric acid, boiling in acetic acid and finally 6 times rinsing with deionized water were $55 \pm 3.8,14 \pm 1.6,32 \pm 2.4,14 \pm 1.1$ and $30 \pm 0.5 \mathrm{ppb}$, respectively. The highest reeducation percent of lead in rice samples was obtained in both soaking with citric acid and boiling with citric acid (84\%). In keeping with the high concentrations of lead in studied rice samples, obtained concentrations were lower than the allowed limit of lead announced with the international standard organization of Iran $(150 \mathrm{ppb})$. Boiling and soaking of rice samples with citric acid $1 \%$ can be a convenient and fast way to reduce the concentration of lead in rice samples.
\end{abstract}

Keywords: rice, cooking process, lead, acetic acid, citric acid

*e-mail: Drmarhamati@gmail.com 


\section{Introduction}

Increasing population and, consequently, industrialization and urbanization of human lifewithout environmental carehas caused an increase in the levels of environmental pollution - especially by toxic heavy metals,including lead $(\mathrm{Pb})$ [1-4]. Mining, industrial processes, pesticides, chemical fertilizers, and atmospheric deposition are the main factors responsible for environmental contamination with lead [1-4].

Lead is the second most important toxic element in the world. It is highly hazardous to human health and may cause acute or chronic poisoning. Chronic exposure to lead has been associated with the induction of pathological changes and damage to organs and the central nervous system, leading to lower intelligence quotients in children [5-8]. It is also responsible for severe damage to kidneys, the pulmonary and gastrointestinal system and bones[5-8]. Chronic exposure with lead also causes the occurrence of cancer and dangerous mutation [5-8]. The International Association of Research for Cancer (IARC) has classified the mineral lead in the $\mathrm{A}_{2}$ carcinogenic group [9].

Plants are the main way of lead transfer from contaminated soils to humans. In a lead-contaminated soil, plants can uptake more heavy metal and accumulate it in different organs - especially edible parts [4]. This phenomenon is especially important for high consumption crops like rice. Rice is mostly used as a main foodstuff in many sites of the world. Rice is the dominant staple food crop in developing countries (including Iran) so that $96 \%$ of the world's rice is produced and consumed in developing countries like Iran $[4-7,10]$. According to the FAO, around 30\% of energy and $20 \%$ of protein sources are provided by consumption of rice [11]. The protein component in rice (7-10\% by weight) is quite low, but it forms a major source of protein (50\%) in countries like Iran [4-7, 10-12]. Rice is also the second-highest consumption food among Iranian people. It is the most common crop grown in agricultural lands in Iran [4-7, 10-12]. Iranian rice has a very good flavor and taste, which has made it easy to export to different parts of the world. Therefore, it is important for rice to be free from toxic heavy metals like lead [4-7, 10-12].

The allowed limit concentration of lead in rice has been announced from 120 to 150 ngg-1 by the National Standards of Iran (ISIRI) and also the Iranian Food and Drug Organization (FDA) [4, 12, 13]. Therefore, it is important to decrease the content of lead in rice less than the allowed limit concentration announced by different organizations. Several methods have been developed for decreasing or eliminating the content of lead in rice [14, 15]. However, none of them arefunctional and cannot be used easily at home. Therefore, it is important to develop a novel method to easily decrease or eliminate the content of residual lead in rice.

According to the high consumption rate of rice among Iranian people, high content of residual lead in rice and lack of applied methods for decreasing the content of lead in rice, the present research was done in order to study the effects of acetic acid and citric acid on concentrations of lead in Iranian rice.

\section{Materials and Methods}

\section{Ethical Approval}

The current research was approved by the Ethical Council of Research of the Faculty of Veterinary Medicine, Islamic Azad University, Science and Research Branch, Tehran, Iran. Verification of this research project and the licenses related to sampling process were approved by Dr. Mohammd Hosein Marhamatizadeh.

\section{Chemical Reagents}

All chemical reagents were purchased from the Meek Company (Merck, Germany). Deionized water with 18.2 million ohm-cm (18.2 megohm) degreewas prepared using a distilled water dispenser (Elga Labwater, Wycombe, Bucks, UK). Standard lead stock solution with concentration of $1000 \mu \mathrm{g} / \mathrm{ml}$ soluble in the nitric acid 0.1 molar $\left(\mathrm{HNO}_{3}\right)$ was purchased from the Spanish Panreac Company (Panreac, Spain). Work standards of lead were prepared in $\mathrm{HNO}_{3}: \mathrm{H}_{2} \mathrm{O}_{2}(5: 2)$ on a daily basis. All equipment were washed using nitric acid 5\% for $24 \mathrm{hrs}$ and then washed twice by deionized water.

\section{Sample Preparation}

Rice samples were purchased from rice farms in northern Iran (Sari, Iran). Preparation of rice samples was done according to traditional cooking in a laboratory prior to lead extraction. All rice samples were primary washed six times using deionized water. Then the concentration of $\mathrm{Pb}$ was measured in washed rice samples. Rice cooking was done in the two forms of Katehand infusion. Ten grams of each sample were taken and washed in deionized water. Then in a beaker, $70 \mathrm{cc}$ of de-ionized water was added to rice grains (1 mL/s flow rate), brought to a boil and heated for $40 \mathrm{~min}$. For the Kateh method, after $40 \mathrm{~min}$, , heat was reduced until all the water evaporated, but for the diffusion method, after $40 \mathrm{~min}$., heat was turned off and rice was separated from water by a drainer. In the Kateh cooking method, the rice samples were soaked separately in citric acid $1 \%$ and acetic acid $1 \%$ for 2 hrs. After soaking, rice samples were washed three times using the deionized water. In the infusion cooking method, rice samples were boiled separately in citric acid $1 \%$ and acetic acid $1 \%$ for $20 \mathrm{~min}$. After boiling, rice samples were washed three times using deionized water. Then the preparation method and lead extraction were carried out according to the standard guidelines of the Association of Official Analysis Chemists [16]. 
Briefly, one gram of rice sample was weighed and $2.5 \mathrm{ml}$ of rinsing solution $\left(\mathrm{MgO} 2 \%+\mathrm{MgNO}_{3} \quad 20 \%\right.$ ) was added to it. Then the contents were placed inside Kruse on heater and the temperature of the heater was gradually raised until the samples were burned and turned black. Then the burnt samples were transferred into an electric furnace. The temperature of the electric furnace was adjusted to $450^{\circ} \mathrm{C}$ for $4 \mathrm{hrs}$. until white ash was obtained. Fifty milliliters of nitric acid solvent $1 \%$ molar were added to obtained ash. The final solution was completely homogeneous and then the obtained extract was injected into the atomic absorption graphite furnace system at a wavelength of 193/7.

\section{Analysis of the Lead Concentration}

Atomic absorption light spectrometer system model AA240FS (Varian, Australia) equipped with graphite furnace model GTA-120 with deuterium lamp was used for this purpose. A Varian program for the solution of injective samples alongside ortho-biosphoric acid $(1000 \mathrm{ml} / \mathrm{l})$ was used as a modifier in the furnace. All experiments were carried out using pyroliticgraphite tubes. Operational parameters for lead were adjusted according to them a nu facture's instructions(width of $0.5 \mathrm{~nm}$, sample volume of $20 \mu 1$, modifier volume of $5 \mu \mathrm{l}$, lamp flow of $10 \mathrm{~mA}$ and wavelength of $283.3 \mathrm{~nm}$ ) [16].

\section{Validation of the Method}

Validation of the experiment was done according to the guidelines of the European Union [17]. The spike calibration curve was drawn in order to study the validation of achieved data and overcome the effect of matrice. The stages of sample preparation and system parameters were determined by adding some analites to blank samples of rice in 3 different work days using the mentioned sample preparation method. One gram of powdered rice with different levels of standard lead (0.5, $2.5,5,10$ and 20) was kept in a dark place for an hour for the purpose of joining more treated toxin to matrice. Then the matrice of samples was analyzed based on the stated analysis method and the results were used to draw the calibration curve. This process was repeated on 3 different days and in the end, the calibration curve was drawn with a mean of 4 points and special software of Espctra.

\section{Study of the Accuracy, Correctness and Percentage of Recycling}

The blank sample free from lead was selected from a type of rice. The samples of blank from grilled rice at concentrations of 25, 50, 100 and 200 were spiked using the work standards. These samples were analyzed and the percentage of recycling was determined using a calibration curve. This process was done during 3 work days and the mean percentage of recycling and the value of $\mathrm{CV} \%$ were used for study the accuracy and correctness.

\section{Results}

We found that the correlation coefficient of calibration curve was 0.996 . The mean percentage of recycling and standard deviation of the lead were obtained $99.5 \%$ and $3.2 \%$, respectively. Detection limit and determination limit for the lowest detectable value by the system were determined by noise signals of 3.1 and 10.1, respectively. Therefore, the LOD and LOQ parameters of applied method for detection of lead were 1 and $3 \mathrm{ppb}$, respectively.

Table 1 represents the results of analysis of lead in contaminated rice samples with the preparation operations. The mean lead concentration in rice samples of the present study was $87 \pm 4.8 \mathrm{ppb}$. The mean concentration of lead in rice samples processed with soaking on acetic acid, soaking with citric acid, boiling with acetic acid and finally boiling with citric acid were $30 \pm 0.5,14 \pm 1.1,32 \pm 2.4$ and $14 \pm 1.1 \mathrm{ppb}$, respectively. The mean concentration of lead in rice samples washed with 6 times deionized water was $55 \pm 3.8 \mathrm{ppb}$. Reduction percent of the lead in rice samples processed with soaking on acetic acid, soaking with citric acid, boiling with acetic acid and finally boiling with citric acid methods were $67 \%, 84 \%, 63 \%$ and $84 \%$, respectively. Reduction percentage of the lead in rice samples washed with 6 times deionized water was 37\%. Fig. 1 represents the mean concentration of lead in operational methods used in this study. Fig. 2 represents the reduction percentage of lead in operational methods used in this study. We found that soaking of rice samples in citric acid $1 \%(2 \mathrm{hrs})$ and boiling with citric acid $1 \%$ ( $2 \mathrm{hrs}$ ) and then their rinsing by deionized water had the highest declining effects on lead concentration. The lowest declining effects was found for 6 times rinsing of rice samples with the deionized water.

\section{Discussion}

Consumption of rice contaminated with heavy metals and especially lead for a long period of time causes severe clinical diseases and syndrome including cancer, chromosomal mutations, and malformation. Therefore, finding a convenient and easy way to reduce the content of residual lead in highly consumed foods and especially rice can prevent the occurrence of such dangerous disorders.

As far as we know, the present study is the first report of the reducing effects of citric acid and acetic acid on the content of residual lead in Iranian rice. We found that using both citric acid and acetic acid caused considerable reducing effects on the content of lead in rice. However, reducing the effect of the citric acid was far more than the acetic acid. We also 
Table 1. Results of analysis of lead in contaminated rice samples with preparation operations $(n=45)$.

\begin{tabular}{|c|c|c|c|c|c|c|c|c|c|}
\hline \multirow[b]{2}{*}{ Sample } & \multirow{2}{*}{$\begin{array}{c}\text { Real } \\
\text { sample }\end{array}$} & \multicolumn{4}{|c|}{ Keeping with acetic acid $1 \%(2 \mathrm{~h})$} & \multicolumn{4}{|c|}{ Keeping up with citric acid $1 \%(2 \mathrm{~h})$} \\
\hline & & $\begin{array}{l}\text { Treatment } \\
\quad(\mathrm{ppb})\end{array}$ & $\begin{array}{l}\text { Reduction } \\
(\%)\end{array}$ & $\begin{array}{c}\text { Mean } \\
(\%)\end{array}$ & SD & $\begin{array}{c}\text { Treatment } \\
\text { (ppb) }\end{array}$ & $\begin{array}{l}\text { Reduction } \\
(\%)\end{array}$ & $\begin{array}{c}\text { Mean } \\
(\%)\end{array}$ & SD \\
\hline \multirow{3}{*}{$\mathrm{S} 1$} & 81 & 30.0 & 63 & \multirow{3}{*}{62.1} & \multirow{3}{*}{0.7} & 13 & 84 & \multirow{3}{*}{83.5} & \multirow{3}{*}{0.7} \\
\hline & 81 & 31.0 & 62 & & & 13 & 84 & & \\
\hline & 81 & 31.0 & 62 & & & 14 & 83 & & \\
\hline \multirow{3}{*}{ S2 } & 89 & 31.0 & 65 & \multirow{3}{*}{65.5} & \multirow{3}{*}{0.6} & 14 & 84 & \multirow{3}{*}{83.5} & \multirow{3}{*}{1.3} \\
\hline & 89 & 31.0 & 65 & & & 14 & 84 & & \\
\hline & 89 & 30.0 & 66 & & & 16 & 82 & & \\
\hline \multirow{3}{*}{ S3 } & 91 & 30.0 & 67 & \multirow{3}{*}{67.0} & \multirow{3}{*}{0.0} & 16 & 82 & \multirow{3}{*}{83.5} & \multirow{3}{*}{1.1} \\
\hline & 91 & 30.0 & 67 & & & 14 & 85 & & \\
\hline & 91 & 30.0 & 67 & & & 15 & 84 & & \\
\hline \multirow[t]{2}{*}{ Total mean } & $87 \pm 4.8$ & $30 \pm 0.5$ & 65 & 65 & 0.5 & $14 \pm 1.1$ & 84 & 84 & 1 \\
\hline & & \multicolumn{4}{|c|}{ Rinse off with acetic acid $1 \%$} & \multicolumn{4}{|c|}{ Rinse off with Citric acid 1\% } \\
\hline Sample & $\begin{array}{c}\text { Real } \\
\text { sample }\end{array}$ & $\begin{array}{l}\text { Treatment } \\
(\mathrm{ppb})\end{array}$ & $\begin{array}{c}\text { Reduction } \\
(\%)\end{array}$ & $\begin{array}{c}\text { Mean } \\
(\%)\end{array}$ & SD & $\begin{array}{c}\text { Treatment } \\
(\mathrm{ppb})\end{array}$ & $\begin{array}{c}\text { Reduction } \\
(\%)\end{array}$ & $\begin{array}{c}\text { Mean } \\
(\%)\end{array}$ & SD \\
\hline \multirow{3}{*}{ S1 } & 81 & 30 & 63 & \multirow{3}{*}{62.6} & \multirow{3}{*}{0.7} & 12 & 85 & \multirow{3}{*}{84.0} & \\
\hline & 81 & 31 & 62 & & & 12 & 85 & & 2.1 \\
\hline & 81 & 30 & 63 & & & 15 & 81 & & \\
\hline & 89 & 35 & 61 & & & 15 & 83 & & \\
\hline S2 & 89 & 35 & 61 & 60.7 & 0.0 & 15 & 83 & 84.3 & 1.9 \\
\hline & 89 & 35 & 61 & & & 12 & 87 & & \\
\hline & 91 & 30 & 67 & & & 12 & 87 & & \\
\hline S3 & 91 & 30 & 67 & 67.0 & 0.0 & 15 & 84 & 84.6 & 1.9 \\
\hline & 91 & 30 & 67 & & & 15 & 84 & & \\
\hline Total mean & $87 \pm 4.8$ & $32 \pm 2.4$ & 63 & 63 & 0.2 & $14 \pm 1.1$ & 84 & 84 & 2 \\
\hline & & & & Wash v & deioni & water $(6$ Tin & & & \\
\hline Sample & $\begin{array}{c}\text { Real } \\
\text { sample }\end{array}$ & $\begin{array}{r}\text { Trea } \\
(\mathrm{p} \\
\end{array}$ & & Red & & $\mathrm{Me}$ & $\%)$ & SI & \\
\hline & 81 & & & & & & & & \\
\hline $\mathrm{S} 1$ & 81 & & & & & & & 0. & \\
\hline & 81 & & & & & & & & \\
\hline & 89 & & & & & & & & \\
\hline $\mathrm{S} 2$ & 89 & & & & & & & 3. & \\
\hline & 89 & & & & & & & & \\
\hline & 91 & & & & & & & & \\
\hline $\mathrm{S} 3$ & 91 & & & & & & & 0. & \\
\hline & 91 & & & & & & & & \\
\hline Total mean & $87 \pm 4.8$ & $55=$ & & & & & & 1. & \\
\hline
\end{tabular}




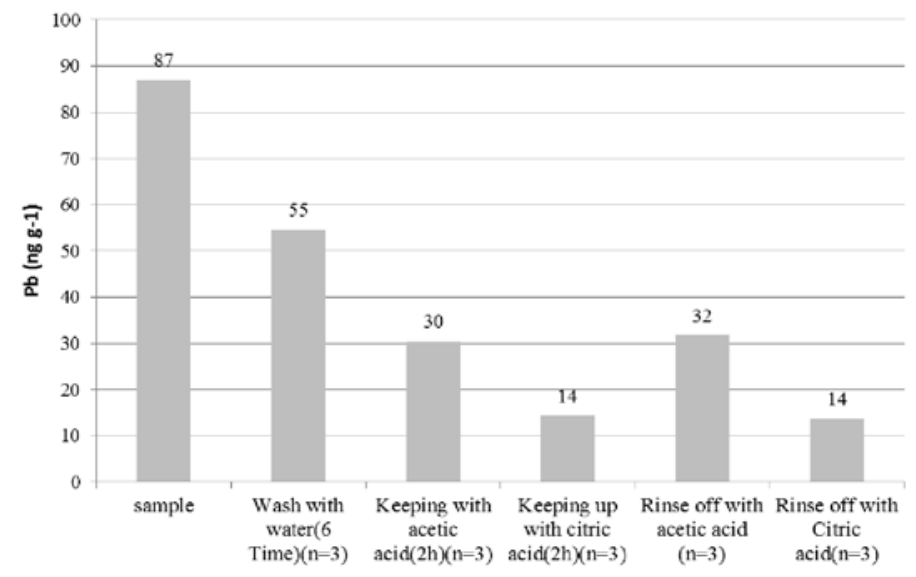

Fig. 1. Comparison of the amount of lead in rice samples processed with different pre-cooking methods.

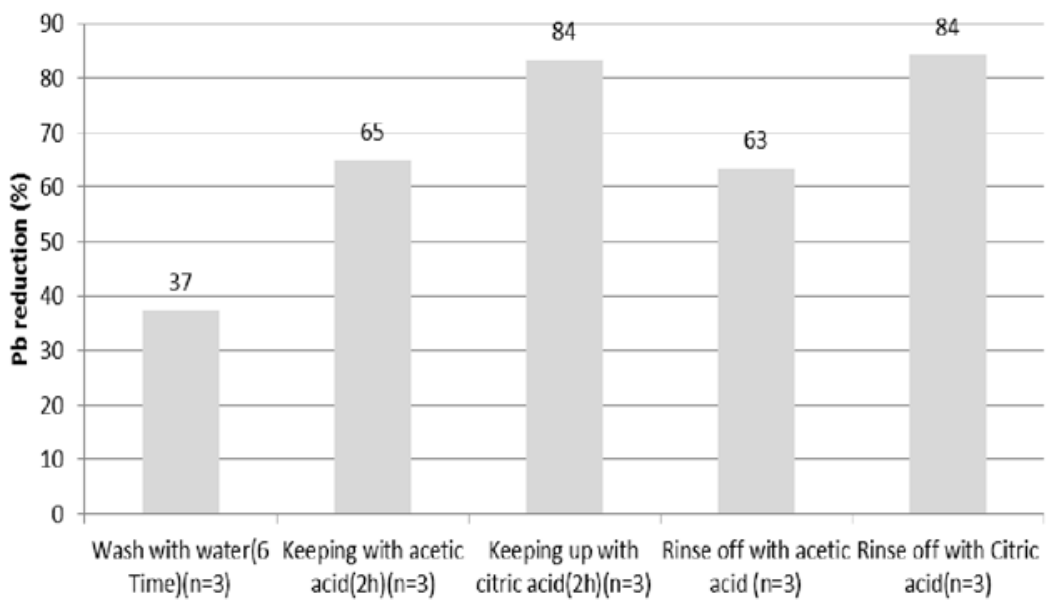

Fig. 2. Comparison of the reduction percentages of lead in rice samples processed with different pre-cooking methods.

found that soaking rice samples with citric acid and also boiling of rice samples with citric acid had the highest reducing effects on the content of lead in rice samples. As it showed, the concentration of residual lead in studied rice samples $(87 \pm 4.8 \mathrm{ppb})$ was lower than the allowed limit concentration as determined by the National Standard Organization of Iran (150 ppb) [18]. Detected concentrations were also lower than the allowed limit concentration announced by the Codex (200 ppb) [19]. It was also lower than the allowed limit concentration determined by the WHO/FAO $(0.3 \mathrm{mg} / \mathrm{kg})$ [20]. However, using the rice samples for a long period of time is a serious risk factor for the occurrence of the mentioned diseases and disorders.

Several studies have been conducted in this field. Naito et al. (2015) [20] reported that rinsing rice three times was sufficient to decrease the content of heavy metals. Researchers showed that the inefficiency of soaking and rinsing methods for decreasing the content of lead in rice samples is perhaps due to different factors affecting the release of lead from the rice, such as $\mathrm{pH}$, solubility, adsorption characteristics and the formation of complexes [14, 21]. The results of our study showed that using citric and acetic acids decreases the content of lead in rice. This is maybe due to the fact that these acids decrease the $\mathrm{pH}$ of rice samples, which leads to the release of lead element. Low $\mathrm{pH}$ may also prevent the formation of complexes [14, 20, 21]. Other studies have reported that temperature degree and time of cooking of foodstuffs and especially rice caused a decrease in the content of chemical contaminants [22-27]. Naseri et al. (2014) [25] reported the considerable effects of Kateh and infusion rice cooking methods on the concentration of lead in rice.

The current study focused on using the popular infusion and Katehrice cooking methods. These methods are affiliated with using boiled water for a considerable period of time. The highest reduction percentage of lead was shown in rinsing preparation method with citric acid $1 \%(84 \%)$ and rice soaking in $1 \%$ citric acid for 2 hours (84\%). However, the lowest decrease in the content of lead was reported forrice rinsed with deionized water (37\%). Therefore, rinsing with citric acid in both modes of infusion and Kateh leads to an $84 \%$ reduction in the content of lead in rice. Signes-Pastor et al. (2017) [28] reported the considerable 
effects of pre-cooking procedures, including rinsing and peeling, on the reduction of heavy metals in foodstuffs. Al-Saleh and Abduljabbar (2017) [29] reported that the mean level of lead in soaked (rinsed) rice gains growth in Saudi-Arabia was $0.034(0.057) \mu \mathrm{g} / \mathrm{g}$ dry weight. They showed that soaking or rinsing rice grains with water decreased lead levels in all brands to safe levels, which supported our findings. Documented data revealed that using the most suitable method to reduce the content of residual lead is dependent on the type of foodstuff, chemical contaminants and time of processing stage [30]. Naseri et al. (2014) [25] reported that the mean concentration of residual lead in rice processed with Kateh and the vapor cooking method and also raw rice samples were $1,0.98$ and $1 \mu \mathrm{g} / \mathrm{g}$, respectively. Similar findings were also reported by Zazouli et al. (2010) [26] and Alberti-Fidanza et al. (2002) [24]. Razafsha and Ziarati (2016) [31] reported that rising and soaking of rice samples in water and then their treatments with sour lemon peel (Biosorbent) and $\mathrm{NaCl} 2 \%$ modified by phosphoric acid $1 \%$ for an hour decreases the content of lead as $90.11 \%$ of its initial. However, the reported method by Razafsha and Ziarati (2016) [31] was practical but it is not applied in homes. Temperature, time and method of cooking were introduced as gold factors for reducing the content of lead in rice [32]. Xu et al. (2014) [33] reported that the content of residual heavy metals in rice in the deep solutions were safe according to the environmental quality standard for groundwater. They showed that irrigation management has a significant effect on the content of residual toxic heavy metals in rice. Tahir Amin et al. (2017) [34] reported that using date palm fibers and orange peel in agricultural lands caused a significant decrease in the content of toxic heavy metals, which showed the effect of management in the content of heavy metals in plans. Razafsha et al. (2016) [35] reported that using sour lemon peel caused a significant decrease in the content of heavy metal in rice. They showed that cooking rice by soaking rinsed rice samples by $\mathrm{NaCl} 2 \%$ and sour lemon peel modified by phosphoric acid $1 \%$ at least for 1 hours had the greatest effect $(P<0.001)$ with regards to lowering lead and cadmium levels in cooked rice. Specifically, it preferentially reduced the cadmium content by $96.40 \%$, nickel content by $67.90 \%$ and Lead content by $90.11 \%$ from the raw rice, when combined with rinse washing and being soaked in salt for one-hour contact time. Similar findings have been reported by the Naseri et al. (2014) [36].

\section{Conclusions}

In conclusion, we identified an easy and safe method based on the soaking and boiling of rice samples in citric acid and acetic acid in order to remove or reduce the content of residual lead in rice samples. We found that the mean concentration of lead in Iranian rice samples was $87 \pm 4.8 \mathrm{ppb}$. We found an $84 \%$ decrease in the content of lead prior to treatment with citric acid. In addition, reducing the effects of acetic acid were also considerable. Citric acid is the main organic acid in lemon juice and acetic acid is the main one in vinegar. Therefore, household soaking and boiling of rice using vinegar and especially lemon juice are efficient, safe, simple and rapid methods for decreasing the content of residual lead in rice.

\section{Acknowledgements}

The authors would like to thank Mr. Hamid Karimaneh for his important support of this research project. We also thank the staff of the Food and Drug Administration of Iran for their laboratory supports. The current research was financially supported by Islamic Azad University, Science and Research Branch, Iran.

\section{Conflict of Interest}

The authors declare no conflict of interest.

\section{References}

1. DARGAHI A., GOLESTANIFAR H., DARVISHI P., KARAMI A., HASAN SH., POORMOHAMMADI A., BEHZADNIA A. An investigation and comparison of removing heavy metals (lead and chromium) from aqueous solutions using magnesium oxide nanoparticles. Pol. J. Environ. Stud. 25 (2), 557, 2016.

2. FARROKHI M., NAIMI-JOUBANI M., DARGAHI A., POURSADEGHIAN M., JAMALI HA. Investigating activated sludge microbial population efficiency in heavy metals removal from compost leachate. Pol. J. Environ. Stud, 27 (2), 623, 2018.

3. ALMASI A., DARGAHI A., AHAGH M., JANJANI H., MOHAMMADI M., TABANDEH L. Efficiency of a constructed wetland in controlling organic pollutants, nitrogen, and heavy metals from sewage. JCHPS, 9 (4), 2924, 2016.

4. CHAMANNEJADIAN A., SAYYAD G., MOEZZI A., JAHANGIRI A. Evaluation of estimated daily intake (EDI) of cadmium and lead for rice (Oryza sativa L.) in calcareous soils.Iran. J. Environ. Healt.h Sci. Engin. 10 (1), 28, 2013.

5. LIN H-T, WONG S-S, LI G-C. Heavy metal content of rice and shellfish in Taiwan. J. Food. Drug. Analysis. 12 (2), 167, 2004

6. CHAMANNEJADIAN A., MOEZZI A., SAYYAD G., JAHANGIRI A., JAFARNEJADI A. Spatial distribution of lead in calcareous soils and rice seeds of Khuzestan, Iran. Malaysian. J. Soil. Sci. 15, 115, 2011.

7. ALAVI S., SHAMSHIRI S., PARIZ Z., DARGAHI A., MOHAMMADI M., FATHI S., AMIRIAN T. Evaluating the palm leaves efficiency as a natural adsorbent for removing cadmium from aqueous solutions: Isotherm adsorption study. IJPT, 8 (2), 13919, 2016.

8. JAISHANKAR M., TSETEN T., ANBALAGAN N., MATHEW B.B., BEEREGOWDA K.N. Toxicity, 
mechanism and health effects of some heavy metals. Interdiscip. Toxicol. 7 (2), 60, 2014.

9. IARC. IARC monograghs on evaluation of carcinogenic risks to humans. In: 5-U01-CA33193. International Agency for Research on Cancer, 2017.

10. MALAKOOTIAN M., YAGHMAEIAN K., MESERGHANI M., MAHVI A. Determination of $\mathrm{Pb}, \mathrm{Cd}$, $\mathrm{Cr}$ and $\mathrm{Ni}$ concentration in imported Indian rice to Iran. Iran. J. Health. Environ. 4 (1), 77, 2011.

11. GILBERT-DIAMOND D., COTTINGHAM K.L., GRUBER J.F., PUNSHON T., SAYARATH V., GANDOLFI A.J., BAKER E.R., JACKSON B.P., FOLT C.L., KARAGAS M.R. Rice consumption contributes to arsenic exposure in US women. Proc. Nat. Acad. Sci. 108 (51), 20656, 2011.

12. KHANIKI G., ZOZALI M. Cadmium and lead contents in rice (Oryza sativa) in the North of Iran. Int. J. Agric. Biol. 6, 1026, 2005.

13. NASERI M., VAZIRZADEH A., KAZEMI R., ZAHERI F. Concentration of some heavy metals in rice types available in Shiraz market and human health risk assessment. Food.Chem. 175, 243, 2015.

14. HAJEB P., SLOTH JJ., SHAKIBAZADEH S., MAHYUDIN N., AFSAH-HEJRI L. Toxic elements in food: Occurrence, binding, and reduction approaches. Comprehensive. Rev. Food. Science. Food. Safety. 13 (4), 457, 2014.

15. BARAKAT M. New trends in removing heavy metals from industrial wastewater. Arab. J. Chem. 4 (4), 361, 2011.

16. JORHEM L., ENGMAN J. Determination of lead, cadmium, zinc, copper, and iron in foods by atomic absorption spectrometry after microwave digestion: NMKL1 collaborative study.J. AOAC. Int. 83 (5), 1189, 2000.

17. LOPES R., BRITO M., GASPAR H., SILVA R. Validation of the quantification of cathinones in plant feeders by $1 \mathrm{H}$ NMR. In.: Eurachem, 2014.

18. ISIRI. Food and Feed-Maximum limit of heavy metals National standard In.: Institute of Standards and Industrial Research of Iran, 2010.

19. Codex. Codex Alimentarius Commission. In.: CODEX STAN, 1-44, 2014.

20. NAITO S., MATSUMOTO E., SHINDOH K., NISHIMURA T. Effects of polishing, cooking, and storing on total arsenic and arsenic species concentrations in rice cultivated in Japan. Food. Chem. 168, 294, 2015.

21. NRC. Drinking Water and Health, vol. 1. Rinsington (DC), USA: National Academies Press (US) Inorganic Solutes, 1977.
22. CAREY M., JIUJIN X., FARIAS J.G., MEHARG A.A. Rethinking rice preparation for highly efficient removal of inorganic arsenic using percolating cooking water. Plos. One. 10 (7), e0131608, 2015.

23. RAAB A., BASKARAN C., FELDMANN J., MEHARG A.A. Cooking rice in a high water to rice ratio reduces inorganic arsenic content. J. Environ. Monitor. 11 (1), 41, 2009.

24. ALBERTI-FIDANZA A., BURINI G., PERRIELLO G. Trace elements in foods and meals consumed by students attending the faculty cafeteria. Sci. Total. Environ. 287 (1), 133, 2002.

25. NASERI M., RAHMANIKHAH Z., BEIYGLOO V., RANJBAR S. Effects of two cooking methods on the concentrations of some heavy metals (cadmium, lead, chromium, nickel and cobalt) in some rice brands available in Iranian Market. J. Chem. Health. Risk. 4 (2), 2014.

26. ZAZOULI M.A., BANDPEI A.M., EBRAHIMI M., IZANLOO H. Investigation of cadmium and lead contents in Iranian rice cultivated in Babol region. Asian. J. Chem. 22 (2), 1369, 2010.

27. ZIARATI P., RABIZADEH H., MOUSAVI Z., ASGARPANAH J., AZARIUN A. The Effect of cooking method in Potassium, lead and Cadmium Contents in Commonly Consumed packaged mushroom (Agaricus bisporus) in Iran. IJFAS. J. 2, 728,2013

28. SIGNES-PASTOR A.J., CAREY M., MEHARG A.A. Inorganic arsenic removal in rice bran by percolating cooking water. Food. Chem. 234, 76, 2017.

29. AL-SALEH I., ABDULJABBAR M. Heavy metals (lead, cadmium, methylmercury, arsenic) in commonly imported rice grains (Oryza sativa) sold in Saudi Arabia and their potential health risk. Int. J. Hygiene. Environ. Health. 220 (7), 1168, 2017

30. KAUSHIK G., SATYA S., NAIK S. Food processing a tool to pesticide residue dissipation - A review. Food. Res. Int. 42 (1), 26, 2009.

31. RAZAFSHA A., ZIARATI P. Removal of Heavy Metals from Oryza sativa Rice by Sour Lemon Peel as Biosorbent. Biomed. Pharmacol. J. 9 (2), 543, 2016.

32. PERELLÓ G., MARTÍ-CID R., LLOBET J.M., DOMINGO J.L. Effects of various cooking processes on the concentrations of arsenic, cadmium, mercury, and lead in foods. J. Agric. Food. Chem. 56 (23), 11262, 2008.

33. NASERI M., RAHMANIKHAH Z., BEIYGLOO V., RANJBAR S. Effects of two cooking methods on the concentrations of some heavy metals (cadmium, lead, chromium, nickel and cobalt) in some rice brands available in Iranian market. J. Chem. Health. Risk, 4 (2), 65, 2014. 